\title{
Contrarreforma, ensino superior público e Serviço Social: quais impactos na formação?
}

\author{
Counter-reformation, public higher education and social work: \\ impacts on training?
}

\author{
Larissa Dahmer Pereira*
}

\begin{abstract}
Resumo - O artigo problematiza os impactos da expansão do ensino superior público na formação em Serviço Social durante os anos 2000, em tempos de contrarreforma do Estado. Foram aplicados questionários junto às coordenações dos cursos criados entre os anos de 1930 e 2002, com o objetivo de identificar as consequências do processo expansivo, por meio do Reuni, durante os governos Lula. Coletamos dados relativos a aspectos da formação profissional, tais como a relação pesquisa, ensino e extensão; a relação da unidade formativa com o projeto de formação da Abepss; a relação entre quantitativo de discentes e docentes; a titulação do corpo docente; as condições de trabalho quanto à estrutura física; e os limites e desafios para uma formação de qualidade. Como resultados, apreendeu-se que a maior parte dos cursos não aderiu ao Reuni, mas sofre dificuldades como sobrecarga de trabalho docente, política de assistência estudantil insuficiente, infraestrutura inadequada e falta de campos e vagas de estágio.

Palavras-chave: contrarreforma do Estado; expansão do ensino superior público; formação profissional; Serviço Social.
\end{abstract}

\begin{abstract}
The article discusses the impacts of the expansion of public higher education on training in social work during the 2000s, in times of state counter-reformation. Questionnaires were applied to the coordinators of courses created between 1930 and 2002, in order to identify the consequences of the expansive process, through the REUNI program, during the Lula administration. We collected data related to professional training, such as the teaching-research-extension relation, the relationship of the training unit with the ABEPSS project, the relationship between the number of students and teachers, faculty qualification, working conditions regarding physical structure, and the limits and challenges for quality training. As a result, it was understood that most courses did not join REUNI, but suffered difficulties such as teaching work overload, insufficient student assistance policy, inadequate infrastructure, and lack of internship vacancies and field variety.

Keywords: counter-reformation of the state; expansion of public higher education; professional qualification; social work.
\end{abstract}

\footnotetext{
* Doutora (2007) em Serviço Social pelo PPGSS/UFRJ. Pós-Doutora em Educação pelo PPGE/UFRJ (2017). Integra o Coletivo de Estudos Marxismo e Educação (COLEMARX - http://www.colemarx.com.br/) e a Rede Universitas - http://www.redeuniversitas.com.br). É professora da Escola de Serviço Social da UFF/Niterói. E-mail: larissadah mer@hotmail.com. ORCID: https://orcid.org/0000-0002-4449-8184.
} 


\section{ReVIStg am p puttg}

\} CONTRARREFORMA, ENSINO SUPERIOR PÚBLICO E SERVIÇO SOCIAL - PEREIRA, L. D.

DOI: $10.12957 /$ REP.2019.45216

\section{Introdução}

Este trabalho problematiza as condições formativas nos cursos públicos de Serviço Social, criados entre a década de 1930 e o ano de 2002, no Brasil. Além disso, é constituinte de projeto de pesquisa sobre a formação profissional nos cursos presenciais públicos e privados de Serviço Social.

O projeto de pesquisa em curso demarca temporalmente a criação dos cursos públicos de Serviço Social em dois grandes períodos: de 1930 a 2002 e de 2003 a 2016. A demarcação temporal justifica-se em função de o segundo período (2003-2016) - ainda que bem mais curto em relação ao primeiro - ter sido o que criou mais da metade de cursos públicos de Serviço Social no país, no contexto de criação do Programa de Apoio a Planos de Reestruturação e Expansão das Universidades Federais (Reuni). ${ }^{1}$

O Reuni, criado por meio do Decreto no 6.096, de 24 de abril de 2007 (BRASIL, 2007), possibilitou efetivamente o crescimento de vagas embora diminuto, se comparado ao crescimento vertiginoso do setor privado - nas instituições federais de ensino superior (Ifes). ${ }^{2}$ O decreto, já no artigo $1^{\circ}$, assim anuncia o seu objetivo:

Art. 1‥Fica instituído o REUNI, com o objetivo de criar condições para a ampliação do acesso e permanência na educação superior, no nível de graduação, pelo melhor aproveitamento da estrutura física e de recursos humanos existentes nas universidades federais. (BRASIL, 2007, n. p. grifos nossos).

A expansão do ensino superior público no país é não somente louvável, mas fundamentalmente necessária: quando abordamos a taxa de acesso da população ao ensino superior e a média de anos de estudo da população com mais de 25 anos, percebemos o quanto a educação expressa a estrutural desigualdade do país:

No país, 11,2\% da população de 25 anos ou mais não tinham instrução; $30,6 \%$ tinham o fundamental incompleto; $9,1 \%$ tinham fundamental completo; $3,9 \%$ tinham ensino médio incompleto; $26,3 \%$ tinham o ensino médio completo e 15,3\% o superior completo. Portanto, mais da metade da população de 25 anos ou mais no Brasil possuíam apenas até o ensino fundamental completo. (IBGE, 2017, n. p. - grifos nossos).

Destaca-se que a educação no Brasil - especialmente no nível superior de ensino - é destituída da dimensão de direito social, com uma das maiores taxas de participação do setor privado mercantil, concentrado

\footnotetext{
1 Já apresentamos e publicamos resultados da pesquisa referente ao segundo grande período, visto que conseguimos o acesso aos dados com maior facilidade. Os dados referentes ao primeiro período (1930 a 2002) serão, portanto, apresentados no presente artigo.

${ }^{2}$ Ver dados em Síntese de Indicadores Sociais 2015 (IBGE, 2015).
} 


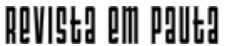

\} CONTRARREFORMA, ENSINO SUPERIOR PÚBLICO E SERVIÇO SOCIAL - PEREIRA, L. D. \}

DOI: $10.12957 /$ REP.2019.45216

em grandes empresas articuladas ao setor financeiro. ${ }^{3}$ Em um contexto de ampliação mercantilizada associada à contrarreforma do Estado brasileiro, desde os anos $1990,{ }^{4}$ a expansão que ocorreu nas Ifes nos anos 2000, conforme já destacado por diversos estudiosos, ${ }^{5}$ assim aconteceu sem a alocação de recursos públicos necessários para que fosse de qualidade. ${ }^{6}$

Desse modo, essa expansão possibilitou o ingresso de uma parcela importante de jovens negros e pertencentes aos grupos mais empobrecidos da classe trabalhadora na universidade, mas se processou com inúmeras contradições: o ensino superior público se ampliou, se interiorizou, abriu as portas para uma parcela negra e mais empobrecida da classe trabalhadora, mas essa mudança ocorreu de forma precarizada, sem os recursos necessários para receber e manter tal público, que conseguiu atravessar as alturas dos muros historicamente elitizados e brancos da universidade brasileira.

No âmbito do Serviço Social, ao levantar dados dos cursos públicos de Serviço Social existentes no país no sistema e-MEC, ${ }^{7}$ encontramos 64 cursos registrados. ${ }^{8}$ Desses, consideramos para análise 29 cursos $^{9}$ criados no período localizado entre a década de 1930 e o ano de 2002, o que representa $46 \%$ da totalidade dos cursos públicos de Serviço Social. ${ }^{10}$ Partimos da hipótese de que os cursos públicos de Serviço Social - criados em período anterior à expansão, isto é, ao Reuni - também foram de algum modo impactados por tal processo, visto que todas as Ifes nas quais se encontram aderiram ao programa, ${ }^{11} \mathrm{com}$ impactos, ainda que indiretos, para cada curso.

Nosso objetivo, aqui, é apreender quais foram os efeitos do processo de expansão do ensino superior em tais cursos já existentes. Ou seja, a questão central que nos norteia na pesquisa é: houve impacto nas condições

\footnotetext{
${ }^{3}$ Ver estudos de Neves (2002) e Neves e Pronko (2008).

${ }^{4}$ Sobre o processo de contrarreforma, ver Behring (2012) e Coutinho (2012). Sobre a relação entre financeirização, fundo público e contrarreforma do Estado brasileiro, ver coletânea organizada por Salvador (2012).

${ }^{5}$ Sobre o modelo de expansão do ensino superior brasileiro, ver estudos de Sguissardi (2008) e (2015) e, ainda, Mancebo, Vale e Martins (2015).

${ }^{6} \mathrm{O}$ que se aprofundará nos próximos anos, com a chamada "PEC do Fim do Mundo", que congelou por 20 anos os gastos públicos. Ver entrevista com Saviani (2017) e análise de Amaral (2016).

7 "Cadastro e-MEC de Instituições e Cursos de Educação Superior, base de dados oficial e única de informações relativas às Instituições de Educação Superior - IES e cursos de graduação do Sistema Federal de Ensino" (EMEC, [20-?].

${ }^{8} \mathrm{O}$ banco de dados do grupo de pesquisa da autora foi criado em 2010 e atualizado para este trabalho com base no e-MEC, entre setembro de 2016 e maio de 2017, pelas discentes bolsistas de iniciação científica, Pibic/CNPq, Faperj e (Proaes e Pibic/CNPq (não identificadas para manter o anonimato), sendo revisados por esta última e pela orientadora das mesmas, autora deste artigo.

${ }^{9}$ Encontramos 64 registros de cursos públicos de Serviço Social no sistema e-MEC. Porém, o curso de Serviço Social da Universidade de Brasília (UnB) possui dois registros, em decorrência da ampliação de vagas em 2010. Assim, não consideramos o registro de 2010, pois o curso da UnB é antigo, da década de 1970. Nesse sentido, contabilizamos 29 cursos para análise no presente trabalho, e não 30.

${ }^{10}$ Isto é, $54 \%$ dos cursos públicos de Serviço Social no país - mais da metade - foram criados entre os anos de 2003 e 2016, em pouco mais de uma década, o que foi analisado em artigo já enviado para publicação em outro periódico.

${ }^{11}$ E aqui é importante destacar que, embora alguns cursos de Serviço Social não tenham aderido ao Reuni, todas as Ifes assinaram os acordos de gestão, o que os impacta (mesmo o curso não tendo aderido), ainda que indiretamente, diante da pressão realizada pelas reitorias pelo aproveitamento dos recursos humanos e da infraestrutura já existente.
} 


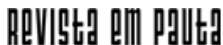

\} CONTRARREFORMA, ENSINO SUPERIOR PÚBLICO E SERVIÇO SOCIAL - PEREIRA, L. D. \}

DOI: $10.12957 /$ REP.2019.45216

formativas em tais cursos a partir do processo de expansão desencadeado nos anos 2000?

Para respondê-la, apresentaremos os resultados de questionários aplicados junto às coordenações de cursos, com posterior problematização. Elegemos os(as) coordenadores(as) de curso como sujeitos da pesquisa ora apresentada, considerando que esses profissionais vivenciam no cotidiano da instituição as consequências diretas do processo de expansão do ensino superior público, nos mais diferentes aspectos. Esses impactos se relacionam com o objetivo do Programa Reuni - ampliar o acesso e permanência na educação superior, aproveitando os recursos humanos e a infraestrutura existente - e suas respectivas diretrizes: redução da evasão, ocupação de vagas ociosas e aumento de vagas de ingresso; revisão da estrutura acadêmica; diversificação das modalidades de graduação; políticas de inclusão e assistência estudantil; e articulação da graduação com a pós-graduação. Ou seja, ainda que as políticas sejam elaboradas pelas Ifes, em suas reitorias/ sub-reitorias, quem é chamado para executá-las e lida com inúmeros limites e desafios no cotidiano junto aos discentes ${ }^{12}$ geralmente é o(a) coordenador(a) de curso.

Dessa maneira, realizamos contato com as 29 coordenações de curso, entre os meses de agosto a dezembro de 2017, por meio de e-mail, telefonemas e redes sociais. Do total de coordenadores(as) de curso, obtivemos o retorno de 19 , o que significa a participação de $65,5 \%$ do universo estudado.

O questionário enviado aos sujeitos da pesquisa objetivou levantar alguns dados preliminares ${ }^{13}$ junto às coordenações dos cursos públicos de Serviço Social, criados antes de 2003, que nos possibilitassem identificar os impactos do processo de expansão do ensino superior público desencadeado durante os governos Lula (2003 a 2010), especialmente a partir da aprovação do Reuni. Teve como propósito coletar dados relativos a aspectos da formação profissional, tais como a relação entre pesquisa, ensino e extensão; a relação da unidade formativa com o projeto de formação profissional da Associação Brasileira de Ensino e Pesquisa em Serviço Social (Abepss); a relação entre quantitativo de discentes e docentes; a titulação do corpo docente; as condições de trabalho quanto à estrutura física; e os limites e desafios frente ao processo de expansão do ensino superior público para uma formação de qualidade nas unidades formativas em análise. Cabe des-

\footnotetext{
${ }^{12}$ Embora esse não seja o objeto do artigo, cabe assinalar que o processo de expansão do ensino superior em sua totalidade, isto é, marcado pela presença esmagadora do setor privado mercantil e com larga oferta de cursos na modalidade EaD, trouxe sérias implicações para os cursos públicos de Serviço Social: a disputa por vagas e campos de estágio pode ser considerada um dos desafios hercúleos e cotidianos das coordenações de curso.

${ }^{13}$ Consideramos como dados preliminares, porque a aplicação de questionários traz algumas limitações quanto à metodologia de pesquisa. Contudo, frente à escassez de recursos para a sua execução, avaliamos que a aplicação de um questionário seria um momento inicial para a realização da pesquisa, tendo clareza quanto à necessidade de maior aprofundamento, com análise documental e entrevistas.
} 


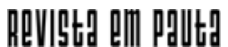

\} CONTRARREFORMA, ENSINO SUPERIOR PÚBLICO E SERVIÇO SOCIAL - PEREIRA, L. D. \}

DOI: $10.12957 /$ REP.2019.45216

tacar que essas unidades não foram identificadas na pesquisa, garantindo o anonimato das mesmas e das coordenações de curso. ${ }^{14}$

\section{Condições formativas nos cursos públicos de Serviço Social criados entre 1930 e 2002}

O primeiro bloco do questionário objetivou conhecer a infraestrutura dos cursos, tais como (i) condições da biblioteca, (ii) equipamentos/ recursos disponíveis aos discentes e (iii) instalações do curso.

Na primeira questão, ao serem indagados quanto à biblioteca, $58 \%$ (11 respostas) apontaram que a consideram satisfatória para as necessidades do curso (Gráfico 1).

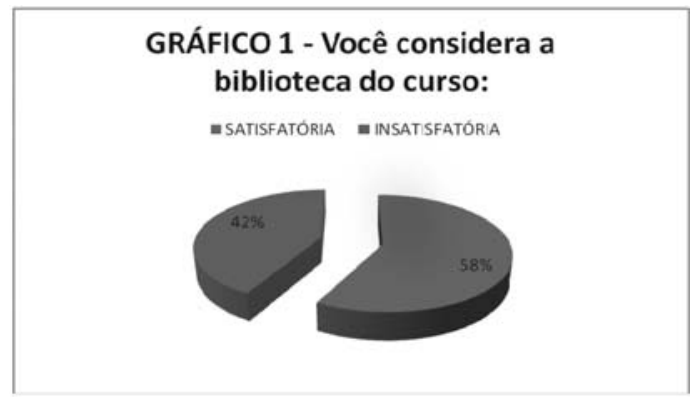

Aos que assinalaram a opção "insatisfatória", ainda referente ao Gráfico 1 (biblioteca), solicitamos que respondessem de forma dissertativa o que identificam como insatisfatório: três sujeitos responderam que (i) o acervo encontra-se desatualizado e com quantitativo insuficiente de exemplares, enquanto que quatro responderam que (ii) o acervo é somente desatualizado.

Em seguida, solicitamos que os sujeitos assinalassem os equipamentos/recursos disponíveis aos discentes na instituição: ${ }^{15}$ bolsas de pesquisa/ extensão (19), restaurante universitário (18), bolsas de assistência (17) e moradia estudantil (15) foram as opções elencadas pela maioria. Em menor proporção, foram assinalados os equipamentos: serviços de saúde (11), transporte estudantil (6), creche (4) e outros (3) (Gráfico 2).

Ao serem questionados quanto às instalações do curso, como sala de professores, salas de aula, salas de pesquisa, auditório, banheiros etc., $58 \%$ dos sujeitos apontaram que as mesmas são adequadas ao desenvolvimento acadêmico (Gráfico 3). Aos oito sujeitos que avaliaram as instalações

\footnotetext{
${ }^{14}$ Gostaríamos de fazer um agradecimento aos coordenadores de curso que, mesmo com intensos afazeres, responderam gentilmente ao questionário.

${ }^{15}$ Os sujeitos puderam marcar várias opções elencadas no questionário.
} 


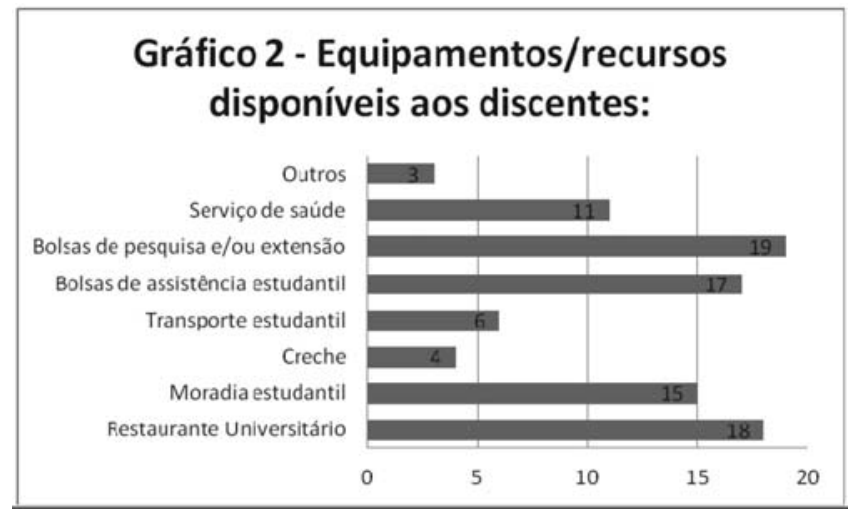

como inadequadas ao desenvolvimento acadêmico, foi solicitada uma resposta dissertativa, explicando o que consideram como "inadequado". Obtivemos as seguintes respostas, ${ }^{16}$ que majoritariamente apontaram a falta de estrutura para atividades extraclasse, como salas de pesquisa/extensão e auditórios e acesso à internet:

No geral nossos equipamentos físicos são antigos e não oferecem acessibilidade.

Temos somente uma sala de reuniões para os grupos de pesquisa se reunirem, por isso, muitas vezes os docentes utilizam suas salas individuais para realização de reuniões de iniciação científica. No início do semestre, nem sempre são alocadas salas de aula para as turmas e preciso acionar a prefeitura.

Torneiras que não funcionam; problemas com ar condicionado; falta de equipamentos; falta pintura nas salas; sem acesso à internet.

Salas de aula sem refrigeração adequada, ambientes de professores sem equipamentos mínimos em termos de infraestrutura e recursos didáticopedagógicos.

Falta: equipar as salas dos docentes, salas de pesquisa aos discentes, auditório com tamanho insuficiente.

Professores/as dividindo sala e ausência de salas para todos os Grupos de Pesquisa.

De uma forma geral a estrutura é adequada. As exceções a se destacar são banheiros e elevadores, que precisam de manutenção/substituição.

\footnotetext{
${ }^{16}$ As falas das coordenações não foram identificadas. Cada citação corresponde à fala de um sujeito pesquisado.
} 


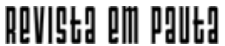

\} CONTRARREFORMA, ENSINO SUPERIOR PÚBLICO E SERVIÇO SOCIAL - PEREIRA, L. D. \}

DOI: $10.12957 /$ REP.2019.45216

Além disso, o auditório do curso deveria ser no andar térreo para garantir melhor acessibilidade ao público.

As salas de aulas são adequadas, inclusive possuem equipamentos multimídia em todas elas. Porém não existem no campus salas específicas para atividades de pesquisa e extensão. Considerando que há um número significativo de grupos de pesquisa e também de extensão há dificuldades para conseguir espaço físico para as atividades.

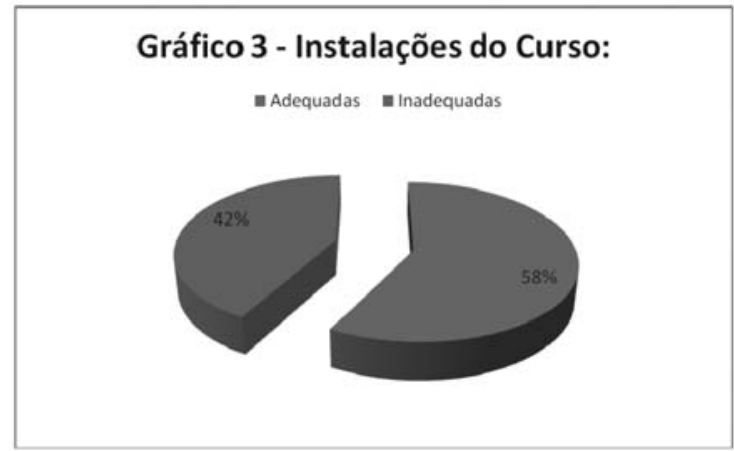

O segundo bloco do questionário aborda o trabalho docente, especialmente se o efetivo de docentes encontra-se em quantidade satisfatória para o exercício do tripé ensino, pesquisa e extensão, o que sem dúvida qualifica o processo formativo de graduandos.

Assim, o Gráfico 4 ilustra um dos problemas crônicos dos cursos públicos: quantitativo insuficiente de docentes, com 63\% (12) dos sujeitos respondendo que a grade semestral não é coberta pela quantidade de docentes existentes no curso. Nessa questão, cabe destacar que perguntamos se o quantitativo de docentes permite a cobertura da grade curricular semestralmente, isto é, a cobertura de somente atividades de ensino, como disciplinas e orientação de trabalho de conclusão de curso (TCC), excetuando pesquisa e extensão.

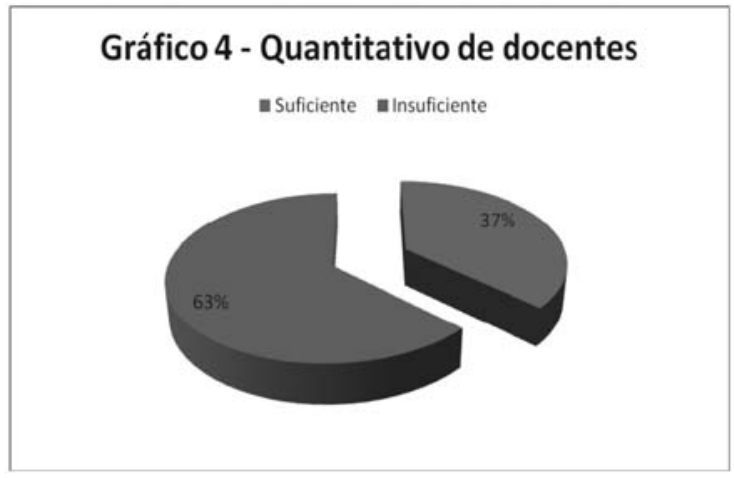




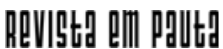

\} CONTRARREFORMA, ENSINO SUPERIOR PÚBLICO E SERVIÇO SOCIAL - PEREIRA, L. D. \}

DOI: $10.12957 /$ REP.2019.45216

Em seguida, perguntamos aos que consideram o quantitativo insuficiente para a cobertura da grade o que o departamento e/ou a coordenação de curso fazem em relação a isso: dos 12 sujeitos que apontaram a insuficiência, dez afirmam abrir seleção periódica para docentes substitutos/temporários e sete informam que alguns docentes assumem mais disciplinas, extrapolando a carga horária semestral (Gráfico 5).

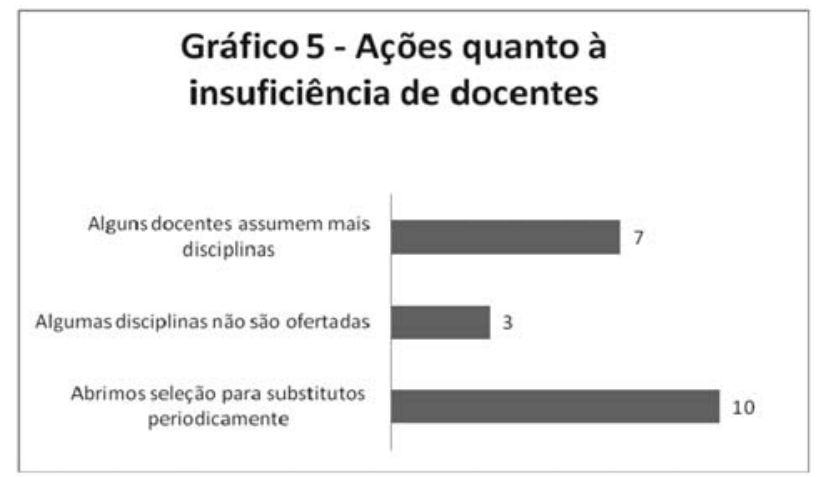

Quanto à distribuição da carga horária docente, 58\% (11) apontaram que, em média, cada docente dedica 20 horas a projetos de pesquisa e/ou extensão, somadas a duas disciplinas de graduação, orientações de TCC e participação em reuniões colegiadas. Para garantir carga horária de atividades de pesquisa e/ou extensão, os docentes não podem extrapolar a carga horária de ensino (disciplinas e TCC) de 20 horas. Contudo, 63\% (Gráfico 4) das coordenações de curso apresentam a insuficiência de docentes para cobertura da grade, buscando então, como arranjo temporário, a contratação de docentes substitutos. Isso, ao nosso ver, fragiliza o processo formativo, visto o vínculo temporário e a não dedicação dos substitutos às atividades de pesquisa e extensão.

Assim, diante da realidade da maior parte dos cursos pesquisados, reitera-se a necessidade de contratação de docentes doutores efetivos para realização do tripé ensino, pesquisa e extensão, sendo crucial para quebrar tal ciclo de fragilidade/precariedade na formação. Essa exigência se relaciona com o necessário investimento público na educação, com a abertura de concursos públicos e criação de infraestrutura adequada para o desenvolvimento do trabalho acadêmico.

O Gráfico 6 nos revela que a maior parte dos docentes de tais cursos já tem a titulação de doutorado, o que reforça a necessidade de contratação de mais docentes e ainda a construção de infraestrutura efetiva (salas de pesquisa e extensão) e disponibilidade de equipamentos para o aproveitamento de um corpo docente tão qualificado. Dos cursos pesquisados, $84 \%$ têm mais de $70 \%$ de doutores em seus quadros docentes, 


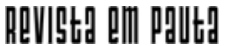

\} CONTRARREFORMA, ENSINO SUPERIOR PÚBLICO E SERVIÇO SOCIAL - PEREIRA, L. D. \}

DOI: $10.12957 /$ REP.2019.45216

sendo que quase a metade (47\%) possui mais de $90 \%$ do seu corpo docente com titulação de doutorado.

A falta de docentes em quantidade suficiente para a cobertura da grade semestral (ensino, com disciplinas e orientação de TCC) faz com que alguns deles se sobrecarreguem e, portanto, fragilizem as atividades de pesquisa e extensão. Tal fato significa o desperdício de uma força de trabalho com alta qualificação, mantida e geralmente formada com recursos públicos nas Ifes.

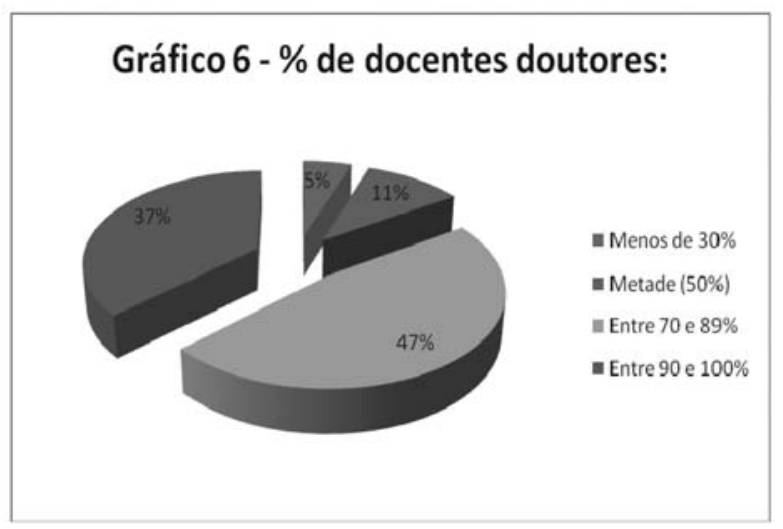

O terceiro bloco de questões refere-se ao corpo discente. Quando questionados sobre a inserção discente em projetos de pesquisa e extensão, $53 \%$ (9) dos sujeitos indicaram que há inserção discente, mas somente uma minoria (entre 10 e $20 \%$ dos discentes) participa de tais atividades. Já $26,3 \%$ (5) informaram que há inserção discente, com participação entre 20 e 50\% do corpo discente em atividades extraclasse (Gráfico 7).

Claro está que, se faltam docentes - na maior parte dos cursos pesquisados - para a cobertura da grade semestral (de disciplinas), não há uma relação adequada entre corpos docente e discente para que a maior parte dos discentes tenha inserção em atividades extraclasse. Especialmente se considerarmos que tais atividades (projetos de pesquisa e extensão) demandam dos docentes um acompanhamento individualizado junto aos discentes, sendo a relação aluno-professor, em tais atividades, muito menor do que a de sala de aula.

O Gráfico 7 relaciona-se claramente com o Gráfico 4 (que demonstra a insuficiência de docentes) e confirma a contradição presente e gritante nesse processo: há significativa qualificação do corpo docente, majoritariamente composta por doutores, sem os recursos humanos em quantidade suficiente para o desenvolvimento adequado do tripé ensino, pesquisa e extensão exigido legalmente para uma instituição universitária. ${ }^{17}$

${ }^{17}$ Conforme art. 52 da Lei de Diretrizes e Bases da Educação Nacional (BRASIL, 1996). 


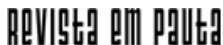

\} CONTRARREFORMA, ENSINO SUPERIOR PÚBLICO E SERVIÇO SOCIAL - PEREIRA, L. D. \}

DOI: $10.12957 /$ REP.2019.45216

O quarto bloco do questionário objetivou apreender a proximidade dos cursos pesquisados com a Abepss, visto que tal entidade defende historicamente uma formação de qualidade, pautada no tripé ensino, pesquisa e extensão, e tem como documentos-base para a formação as Diretrizes Curriculares da Abepss, de 1996 (ABEPSS/CEDEPSS, 1996), e a Política Nacional
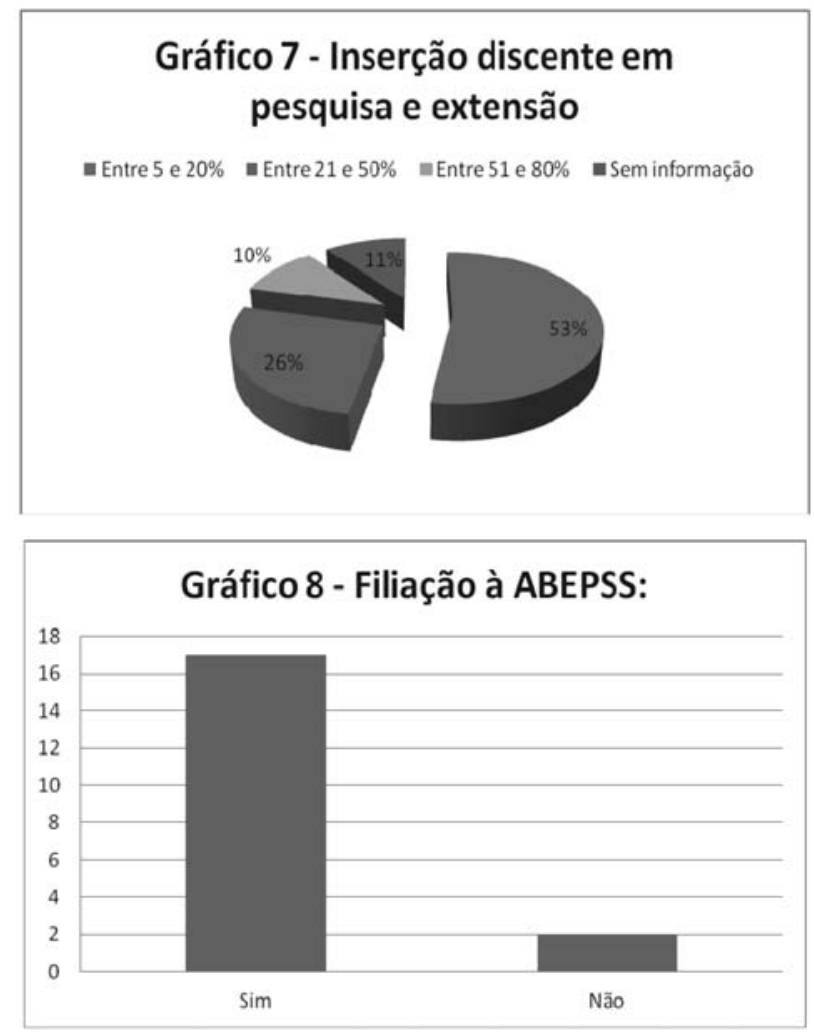

de Estágio (PNE) (ABEPSS, 2008). Cabe ressaltar que, dos dezenove cursos pesquisados, 17 (89\%) são filiados à Abepss.

Ao serem questionados quanto ao cumprimento da Política Nacional de Estágio da Abepss, dos 19 coordenadores de curso consultados, $17(89 \%)$ responderam positivamente, o mesmo percentual de filiação à Abepss, sendo que $11 \%$ afirmam cumprir "parcialmente" à PNE/Abepss.

Os dois cursos que responderam cumprir "parcialmente" a PNE/ Abepss, quando questionados sobre o que não cumpriam, assim responderam $^{18}$ :

${ }_{18}^{18}$ As falas das coordenações não foram identificadas. 


\section{ReVIIStR PMI PaUtD}

\} CONTRARREFORMA, ENSINO SUPERIOR PÚBLICO E SERVIÇO SOCIAL - PEREIRA, L. D. \}

DOI: $10.12957 /$ REP.2019.45216

Supervisão acadêmica do estágio com número maior [de discentes] do que o indicado pela PNE.

O curso tem avançado substancialmente no cumprimento da PNE. No entanto, duas questões precisam ser destacadas. Temos conseguido, frequentemente, respeitar o limite de até 15 (quinze) discentes em turmas de $\mathrm{SAE}$, salvo raras exceções quando há problemas para cobrir a grade. Outra questão que nos desafia, pela mesma razão, refere-se ao acompanhamento dos discentes em estágio não-obrigatório, que tem se dado por meio de acompanhamento direto da coordenação de estágio, diante da dificuldade em ofertar uma disciplina para esta finalidade.

O quinto bloco do questionário objetivou verificar junto às coordenações de curso se as dificuldades apontadas no processo formativo como sobrecarga no trabalho docente, falta de vagas e de campos de estágio e, ainda, dificuldades relacionadas à falta de infraestrutura e de equipamentos coletivos - teriam alguma relação com o processo de expansão desencadeado nos anos 2000 via Reuni.

Quando questionados se o curso aderiu ao processo de expansão do ensino superior por meio do Reuni, a maioria das coordenações de curso $-73,7 \%, 14$ cursos -respondeu que não. Os cinco cursos que responderam ter aderido ao Reuni informaram o seguinte aumento de vagas:

Passamos de 30 (trinta) vagas para 40 (quarenta) por semestre, expandidas no curso vespertino.

O curso dobrou a oferta, chegando a quase 600 alunos matriculados.

Quarenta vagas [anuais, foi aberto o curso noturno].

Tínhamos até então 45 vagas anuais para discentes. Com a reestruturação, ampliamos mais 55 vagas, totalizando 100 no total [anuais].

O REUNI possibilitou a ampliação de $30 \%$ das vagas do curso noturno.

Cinco coordenações de curso registraram a seguinte informação, ${ }^{19}$ explicitando por que não aderiram ao Reuni: ${ }^{20}$

A expansão de vagas não se relacionou ao REUNI, mas à decisão interna da unidade em oferecer mais vagas num curso público e noturno [tratase de curso inserido em universidade estadual].

O aumento de vagas no curso foi anterior à adoção do Reuni pela universidade.

\footnotetext{
${ }_{19}$ O espaço para comentários após a pergunta sobre o aumento de vagas em caso de adesão ao Reuni era livre para todos os respondentes.

${ }^{20}$ Dos dezenove cursos participantes da pesquisa, seis são estaduais e, portanto, não participam do Programa Reuni, visto este ser um programa federal dedicado às Ifes.
} 


\section{ReVl|stg am Patte}

\} CONTRARREFORMA, ENSINO SUPERIOR PÚBLICO E SERVIÇO SOCIAL - PEREIRA, L. D. \}

DOI: $10.12957 /$ REP.2019.45216

É importante esclarecer que nosso curso está inserido em universidade estadual. Portanto, não participou do REUNI [trata-se de curso inserido em universidade estadual].

O nosso curso realmente não aderiu ao REUNI, sendo um dos poucos na Universidade a fazer isso. Entretanto, antes mesmo da adesão pela Universidade o curso já passava por um processo de expansão. [...] Significa que nossa expansão se deu anterior à adesão ao Reuni pela Universidade, consequentemente nossas dificuldades são anteriores e se estendem até hoje porque não conseguimos expandir o número de professores, mesmo com um programa de pós-graduação consolidado, não conseguimos recursos para a melhoria dos equipamentos de trabalho, nem a construção de um bloco de sala de aula próprio, com acessibilidade e vinculado ao prédio administrativo do curso.

É importante esclarecer que houve uma expansão do acesso de estudantes provenientes da classe trabalhadora em decorrência das ações afirmativas (estudantes de escolas públicas e cotas raciais) que atualmente perfazem o total de $35 \%$ das vagas. Para a universidade aderir às ações afirmativas houve um acordo com o governo do Estado que se prontificou em ampliar os recursos para a universidade poder arcar com a ampliação da assistência estudantil, porém isso não ocorreu. $O$ fato é que em virtude de problemas financeiros alegados pela reitoria da universidade, houve diminuição de bolsas e recursos para o Restaurante Universitário. Portanto, os cursos, mas principalmente o Curso de Serviço Social, pelo perfil socioeconômico dos estudantes, tem enfrentando evasão escolar, fenômeno que não havia sido registrado na história do referido curso até então [trata-se de curso inserido em universidade estadual].

Dos cinco cursos que informaram adesão ao Reuni, quatro (80\%) informaram ter recebido vagas docentes como contrapartida. Bolsas estudantis foram indicadas por somente um curso $(20 \%)$, assim como salas de aula, também por somente um curso (20\%).

O Gráfico 10 ilustra os limites identificados pelas coordenações de curso para uma formação profissional de qualidade, pautada nas Diretrizes Curriculares da Abepss, considerando o contexto de expansão do ensino superior. "Escassez de bolsas estudantis e de equipamentos coletivos para que os discentes permaneçam na instituição" foi a opção marcada pela maioria dos respondentes: 16 (84,2\%). Em seguida, a opção "falta de vagas e de campos de estágio qualificados" foi a mais indicada, com dez coordenações $(52,6 \%)$ apontando tal limite. "A falta de docentes, para atividades de ensino, pesquisa e extensão" foi a terceira opção mais marcada: nove $(47,4 \%)$. "Infraestrutura do campus falha para acomodar discentes, docentes e técnico-administrativos" foi indicada por sete $(36,8 \%)$ coordenações. A "insegurança no campus" foi indicada por três coordenações. "Dificuldade de liberação de docentes para qualificação" e "docentes ainda com pouca qualificação para atividades de pesquisa e extensão" foram marcados, ambos, por somente uma coordenação de curso. Uma coordenação de curso res- 


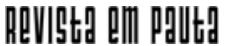

\} CONTRARREFORMA, ENSINO SUPERIOR PÚBLICO E SERVIÇO SOCIAL - PEREIRA, L. D. \}

DOI: $10.12957 /$ REP.2019.45216

pondeu que "temos problemas como as demais Universidades federais, especialmente na atual conjuntura, mas a formação - até o momento - não tem sido impactada, graças ao esforço dos/as docentes".

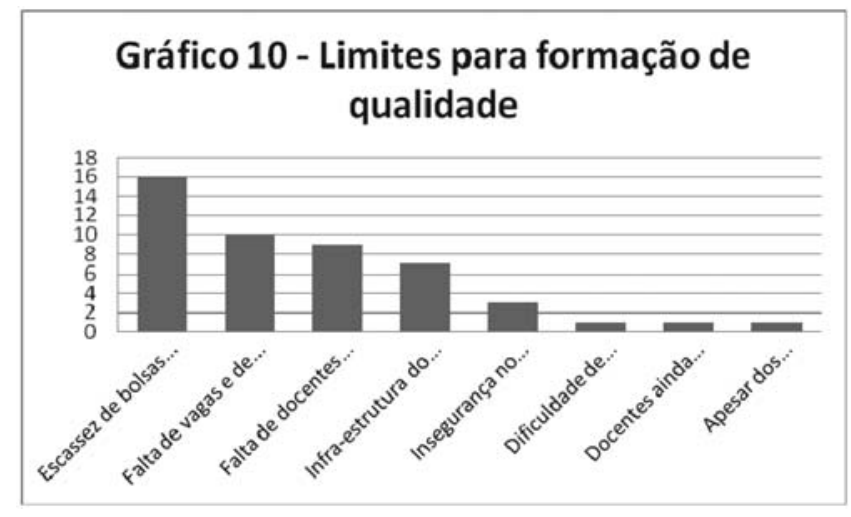

O bloco relativo ao Reuni terminou com a seguinte questão, a ser respondida livremente, de forma dissertativa: "Na condição de Coordenador(a) do Curso, caso o curso tenha expandido suas vagas no período REUNI, relacione as dificuldades assinaladas anteriormente [Gráfico 10] com o processo de expansão. Há relação direta ou são dificuldades anteriores ao REUNI?"

A abertura do curso noturno trouxe desafios tanto no que diz respeito ao quantitativo insuficiente de docentes que foram contratados para atuar nos dois cursos, como falta de infraestrutura adequada.

Corpo discente cresceu para além das capacidades do corpo docente, gerando salas lotadas, retenção e evasão. Foi realizado um ajuste de vagas entre 2012 e 2013, reduzindo a oferta, para adequação à capacidade docente.

Existem problemas anteriores ao REUNI, mas que foram asseverados no decorrer do processo. Inicialmente, sinalizou-se o acréscimo de oito vagas docentes, contudo somente cinco foram efetivadas, o que compromete o funcionamento do curso até o presente momento.

As dificuldades são, sobretudo, para que esse aluno consiga se manter na universidade com garantia de que ele tenha acesso a textos, livros, transporte, alimentação, etc... Com a ampliação das vagas o perfil dos estudantes também mudou, possibilitando o ingresso de estudantes das camadas mais pauperizadas da classe trabalhadora. De um lado, é um ganho enorme, de outro esse estudante tem pouco estímulo para permanecer na universidade e acaba tendo muita dificuldade para se adaptar ao universo acadêmico. Essa situação tem criado um estranhamento por parte desses estudantes do universo acadêmico gerando muitas vezes 


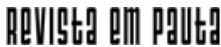

\} CONTRARREFORMA, ENSINO SUPERIOR PÚBLICO E SERVIÇO SOCIAL - PEREIRA, L. D. \}

DOI: $10.12957 /$ REP.2019.45216

um intenso desconforto com a estrutura burocrática, impessoal e muitas vezes elitista do ambiente universitário, o que tem ocasionado vários casos de depressão e outros problemas psicológicos.

Por fim, solicitamos que cada coordenador(a) de curso indicasse o que identifica como principais desafios para que o curso forme assistentes sociais bem qualificados e pautados no Código de Ética Profissional (CFESS, 1993). De dezenove respostas, as quatro mais recorrentes foram: (i) a necessidade de mais docentes; (ii) garantir a política de assistência estudantil para a permanência discente; (iii) expandir e qualificar vagas/campos de estágio e (iv) enfrentar, de modo geral, a precarização do ensino superior. Com menor recorrência, foram indicados os seguintes desafios: (i) reagir às exigências de produtividade acadêmica; (ii) melhorar o apoio aos discentes no atendimento em saúde mental; (iii) pautar a formação nas Diretrizes da Abepss e na PNE/Abepss; (iv) manter de forma contínua a avaliação do projeto pedagógico do curso; (iv) conhecer o perfil do alunado; (v) expandir bolsas de pesquisa e extensão; e (vi) qualificar docentes.

\section{Considerações finais}

O trabalho objetivou apresentar, de forma sintética, a pesquisa realizada junto às coordenações dos cursos públicos de Serviço Social, criados entre os anos de 1930 e 2002. Buscamos apreender as condições formativas em tais cursos e se os mesmos sofreram impactos decorrentes do processo de expansão do ensino superior público desencadeado a partir dos anos 2000 e, especialmente, após o Reuni.

A maior parte dos sujeitos pesquisados afirmou que não houve adesão do curso ao Reuni, indicando filiação à Abepss e cumprimento da PNE/Abepss, com avaliação satisfatória da infraestrutura e instalações para os corpos discente/docente. Outra informação importante diz respeito à alta qualificação do corpo docente dos cursos pesquisados, majoritariamente composto por doutores.

Quanto às dificuldades apontadas, foram indicadas de forma preponderante: (i) a sobrecarga de trabalho docente para o efetivo exercício do tripé ensino, pesquisa e extensão; (ii) a dificuldade de permanência dos estudantes com qualidade na instituição; (iii) a parca inserção discente em atividades extraclasse; e (iv) a qualidade/quantidade de vagas e campos de estágio.

As informações e avaliações colhidas junto às coordenações de curso nos permitem afirmar que tais cursos apresentam enorme potencial formativo, com quadro docente extremamente qualificado, e que se identificam com o perfil de formação propugnado pela Abepss. Contudo, para o seu alcance, é necessário ampliar as ações para além da categoria pro- 


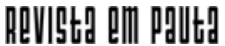

\} CONTRARREFORMA, ENSINO SUPERIOR PÚBLICO E SERVIÇO SOCIAL - PEREIRA, L. D. \}

DOI: $10.12957 /$ REP.2019.45216

fissional, isto é, trata-se de fortalecer a luta mais ampla por concursos públicos, valorização da carreira docente e da educação pública, desenvolvimento de uma política de assistência estudantil que possibilite efetivamente a permanência dos discentes com qualidade e, ainda, intensa articulação política com supervisores dos campos de estágio, qualificando a relação entre universidades e campos de estágio. 


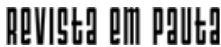

\} CONTRARREFORMA, ENSINO SUPERIOR PÚBLICO E SERVIÇO SOCIAL - PEREIRA, L. D. \}

DOI: $10.12957 /$ REP.2019.45216

\section{Referências}

ABEPSS. Política Nacional de Estágio. Brasília, 2010. Disponível em: http:/ /www.abepss.org.br/arquivos/textos/documento_2016033111453681 98230.pdf. Acesso em: 12 fev. 2018.

ABEPSS; CEDEPSS. Diretrizes gerais para o Curso de Serviço Social. Rio de Janeiro, nov. 1996. Disponível em: http://www.abepss.org.br/arquivos/textos/ documento_201603311138166377210.pdf. Acesso em: 7 fev. 2018.

AGÊNCIA DE NOTÍCIAS. PNAD Contínua 2016: 51\% da população com 25 anos ou mais do Brasil possuíam apenas o ensino fundamental completo. 21 dez. 2017. Disponível em: https://agenciadenoticias.ibge.gov.br/agencianoticias/2013-agencia-de-noticias/releases/18992-pnad-continua-2016-51da-populacao-com-25-anos-ou-mais-do-brasil-possuiam-apenas-o-ensinofundamental-completo.html. Acesso em: 7 fev. 2018.

AMARAL, N. C. PEC 241/55: a "morte" do PNE (2014-2024) e o poder de diminuição dos recursos educacionais. Revista Brasileira de Política e Administração da Educação, v. 32, n. 3, dez. 2016. Disponível em: http:// seer.ufrgs.br/index.php/rbpae/article/view/70262. Acesso em: 7 fev. 2018.

BEHRING, E. R. Brasil em contrarreforma - Desestruturação do Estado e perda de direitos. São Paulo: Cortez Editora, 2012.

BRASIL. Lei n. 9.394, de 20 de dezembro de 1996. Estabelece as diretrizes e bases da educação nacional. Brasília, 1996. Disponível em: http://portal.mec.gov.br/seesp/arquivos/pdf/lei9394_ldbn1.pdf. Acesso em: 7 fev. 2018.

BRASIL. Decreto n. 6.096, de 24 de abril de 2007. Institui o Programa de Apoio a Planos de Reestruturação e Expansão das Universidades Federais Reuni. Brasília, 2007. Disponível em: http://www.planalto.gov.br/ccivil_03/ _ato2007-2010/2007/decreto/d6096.htm. Acesso em: 4 fev. 2018.

CFESS. Resolução CFESS n. 273/93, de 13 de março de 1993. Institui o código de ética profissional e dá outras providências. 1993. Disponível em: http://www.cfess.org.br/arquivos/CEP_CFESS-SITE.pdf. Acesso em: 2 fev. 2018.

COUTINHO, C. N./ A época neoliberal: revolução passiva ou contrarreforma? Revista Novos Rumos, v. 49, n. 1, 2012. Disponível em: http:/ /www2.marilia.unesp.br/revistas/index.php/novosrumos/article/view/2383/ 1943. Acesso em: 23 jan. 2017.

E-MEC. [20—?]. Disponível em: http://emec.mec.gov.br/. Acesso em: 13 nov. 2017

IBGE. Síntese de indicadores sociais: uma análise das condições de vida da população brasileira - 2015. Rio de Janeiro: IBGE, 2015. 


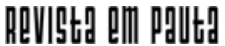

\} CONTRARREFORMA, ENSINO SUPERIOR PÚBLICO E SERVIÇO SOCIAL - PEREIRA, L. D. \}

DOI: $10.12957 /$ REP.2019.45216

MANCEBO, D.; VALE, A. A. do; MARTINS, T. B. Políticas de expansão da educação superior no Brasil 1995-2010. Revista Brasileira de Educação, v. 20 n. 60 jan./mar. 2015. Disponível em: http://www.scielo.br/pdf/rbedu/ v20n60/1413-2478-rbedu-20-60-0031.pdf. Acesso em: 6 fev. 2018.

NEVES, L. M. W. (org.). O empresariamento da educação: novos contornos do ensino superior no Brasil dos anos 1990. São Paulo: Xamã, 2002.

NEVES, L. M. W.; PRONKO, M. A. O mercado do conhecimento e o Conhecimento para o mercado. Rio de Janeiro: Fundação Oswaldo Cruz, 2008. Disponível em: http://www.epsjv.fiocruz.br/sites/default/files/l40.pdf. Acesso em: 11 maio 2017.

SALVADOR, E. et al. Financeirização, fundo público e política social. São Paulo: Cortez, 2012.

SAVIANI, D. PEC do Teto dos Gastos inviabilizou a educação pública no país, diz Dermeval Saviani. 2017. Disponível em: https://www.brasildefato. com.br/2017/12/08/pec-do-teto-dos-gastos-inviabilizou-a-educacao-pubicano-brasil-diz-dermeval-saviani/. Acesso em: 6 fev. 2018.

SGUISSARDI, V. Modelo de expansão da educação superior no Brasil: predomínio privado/mercantil e desafios para a regulação e a formação universitária. Revista Educação e Sociedade, Campinas, v. 29, n. 105, set./dez. 2008. Disponível em: http://www.scielo.br/pdf/es/v29n105/v29n105a04.pdf. Acesso em: 10 jul. 2017.

SGUISSARDI, V. Educação superior no Brasil. Democratização ou massificação mercantil? Revista Educação e Sociedade, Campinas, 2015, v. 36, n. 133, 2015. Disponível em: http://www.scielo.br/scielo.php?script $=$ sci_arttext $\&$ pid $=$ S0101-73302015000400867\&lng=en \&nrm=iso\&tlng=pt. Acesso em: 6 fev. 2018.

DOI: $10.12957 /$ rep.2019.45216

Recebido em 15 de março de 2019.

Aprovado para publicação em 02 de abril de 2019.

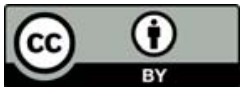

A Revista Em Pauta: Teoria Social e Realidade Contemporânea está licenciada com uma Licença Creative Commons Atribuição 4.0 Internacional. 